\title{
$\triangle$-CONVERGENCE THEOREMS FOR INVERSE-STRONGLY MONOTONE MAPPINGS IN CAT(0) SPACES
}

\author{
SATTAR ALIZADEH* ${ }^{*}$ HOSSEIN DEHGHAN** AND FRIDOUN MORADLOU*** \\ * Department of Mathematics, Marand Branch \\ Islamic Azad University, Marand, Iran \\ E-mail: salizadeh@marandiau.ac.ir, s_alizadeh_s@yahoo.com \\ ** Department of Mathematics \\ Institute for Advanced Studies in Basic Sciences (IASBS) \\ Gava Zang, Zanjan 45137-66731, Iran \\ E-mail: hossein.dehgan@gmail.com \\ *** Department of Mathematics, Sahand University of Technology \\ Tabriz, Iran \\ E-mail: moradlou@sut.ac.ir, fridoun.moradlou@gmail.com
}

\begin{abstract}
In this paper, we first define and study inverse-strongly monotone mappings in general metric spaces. Then, we prove the existence theorem of solutions for variational inequalities involving such mappings. Finally, we introduce an iterative process for finding a common element of the set of fixed points of a nonexpansive mapping and the set of solutions of a variational inequality problem for inverse-strongly monotone mappings in CAT(0) metric spaces.

Key Words and Phrases: inverse-strongly monotone mapping; nonexpansive mapping; variational inequality; fixed point; CAT $(0)$ metric space.

2010 Mathematics Subject Classification: 47H09, 47H10, 47J20, 47J25.

Acknowledgements. The authors would like to thank Marand Branch, Islamic Azad University for the Financial support of this research, which is based on a research project contract. Also, the authors would like to thank the referee(s) for precise consideration and valuable comments.
\end{abstract}

\section{REFERENCES}

[1] C. Baiocchi, A. Capelo, Variational and Quasi-Variational Inequalities, Wiley, New York, 1984.

[2] W. Ballmann, Lectures on Spaces of Nonpositive Curvature, in: DMV Seminar Band, vol. 25, Birkhäuser, Basel, 1995.

[3] I.D. Berg, I.G. Nikolaev, Quasilinearization and curvature of Alexandrov spaces, Geom. Dedicata, 133(2008), 195-218.

[4] M. Bridson, A. Haefliger, Metric Spaces of Nonpositive Curvature, Springer-Verlag, Berlin, Heidelberg, New York, 1999.

[5] F.E. Browder, W.V. Petryshyn, Construction of fixed points of nonlinear mappings in Hilbert Spaces, J. Math. Anal. Appl., 20(1967), 197-228.

${ }^{*}$ Corresponding author. 
[6] L.C. Ceng, Q.H. Ansari, J.C. Yao, On relaxed viscosity iterative methods for variational inequalities in Banach spaces, J. Comput. Appl. Math., 230(2009), 813-822.

[7] R.W. Cottle, F. Giannessi, J.L. Lions, Variational Inequalities and Complementarity Problems: Theory and Applications, Wiley, New York, 1980.

[8] H. Dehghan, J. Rooin, A characterization of metric projection in CAT(0) spaces, arXiv:1311.4174v1, 2013.

[9] S. Dhompongsa, W.A. Kirk, B. Sims, Fixed points of uniformly lipschitzian mappings, Nonlinear Anal., 65(2006), 762-772.

[10] S. Dhompongsa, W.A. Kirk, B. Panyanak, Nonexpansive set-valued mappings in metric and Banach spaces, J. Nonlinear and Convex Anal., 8(2007), 35-45.

[11] S. Dhompongsa, B. Panyanak, On $\Delta$-convergence theorems in CAT(0) spaces, Comput. Math. Appl., 56(2008), 2572-2579.

[12] F. Giannessi, G. Mastroeni, X.Q. Yang, A survey on vector variational inequalities, Boll. Unione Mat. Ital., 9(1)(2009), 225-237.

[13] B.A. Kakavandi, Weak topologies in complete CAT(0) metric spaces, Proc. Amer. Math. Soc., 141(2013), 1029-1039.

[14] W.A. Kirk, Some recent results in metric fixed point theory, J. Fixed Point Theory Appl., 2(2007), 195-207.

[15] W.A. Kirk, B. Panyanak, A concept of convergence in geodesic spaces, Nonlinear Anal., 68(2008), 3689-3696.

[16] W. A. Kirk, Geodesic geometry and fixed point theory, in Seminar of Mathematical Analysis (Malaga/Seville, 2002/2003), vol. 64 of Colecc. Abierta, University of Seville, Secretary Publication, Seville, Spain, (2003), 195-225.

[17] T.C. Lim, Remarks on some fixed point theorems, Proc. Amer. Math. Soc., 60(1976), 179-182.

[18] F. Liu, M.Z. Nashed, Regularization of nonlinear ill-posed variational inequalities and convergence rates, Set-Valued Analysis, 6(1998), 313-344.

[19] G. Marino, H.K. Xu, Explicit hierarchical fixed point approach to variational inequalities, J. Optim. Theory. Appl., 149(2011), 61-78.

[20] A. Papadopoulos, Metric spaces, convexity and nonpositive curvature, IRMA Lectures in Mathematics and Theoretical Physics, 6. European Mathematical Society (EMS), Zürich, 2005.

[21] W. Takahashi, T. Toyoda, Weak convergence theorems for nonexpansive mappings and monotone mappings, J. Optim. Theory. Appl., 118(2003), 417-428.

[22] W. Takahashi, T. Tamura, Convergence theorems for a pair of nonexpansive mappings, J. Convex Anal., 5(1998), 45-56.

[23] H. Zhou, Convergence theorems of fixed points for $\kappa$-strict pseudo-contractions in Hilbert spaces, Nonlinear Anal., 69(2008), 456-462.

Received: September 2, 2015; Accepted: February 12, 2016. 